\section{OPEN ACCESS}

Edited and reviewed by: George E. Billman,

The Ohio State University,

United States

*Correspondence:

Andreas Fahlman afahlman@whoi.edu

Specialty section: This article was submitted to Physio-logging, a section of the journal

Frontiers in Physiology

Received: 18 February 2021 Accepted: 26 February 2021 Published: 30 March 2021

Citation:

Fahlman A, Aoki K, Bale G, Brijs J, Chon KH, Drummond CK, Føre M, Manteca X, McDonald BI,

McKnight JC, Sakamoto KQ, Suzuki I, Rivero MJ, Ropert-Coudert Y and Wisniewska DM (2021) The New Era of Physio-Logging and Their Grand

Challenges.

Front. Physiol. 12:669158 doi: 10.3389/fphys.2021.669158

\title{
The New Era of Physio-Logging and Their Grand Challenges
}

\begin{abstract}
Andreas Fahlman ${ }^{1 *}$, Kagari Aoki ${ }^{2}$, Gemma Bale ${ }^{3}$, Jeroen Brijs ${ }^{4}$, Ki H. Chon ${ }^{5}$, Colin K. Drummond ${ }^{6}$, Martin Føre ${ }^{7}$, Xavier Manteca ${ }^{8}$, Birgitte I. McDonald ${ }^{9}$, J. Chris McKnight ${ }^{10}$, Kentaro Q. Sakamoto ${ }^{2}$, Ippei Suzuki ${ }^{11}$, M. Jordana Rivero ${ }^{12}$, Yan Ropert-Coudert ${ }^{13}$ and Danuta M. Wisniewska ${ }^{14}$
\end{abstract}

\begin{abstract}
${ }^{1}$ Fundación Oceanográfic de la Comunitat Valenciana, Valencia, Spain, ${ }^{2}$ Department of Marine Bioscience, Atmosphere and Ocean Research Institute, The University of Tokyo, Kashiwa, Japan, ${ }^{3}$ Department of Physics and Department of Engineering, University of Cambridge, Cambridge, United Kingdom, ${ }^{4}$ Hawai'i Institute of Marine Biology, University of Hawai'i at Manoa, Manoa, HI, United States, ${ }^{5}$ Biomedical Engineering, University of Connecticut, Storrs, CT, United States, ${ }^{6}$ Biomedical Engineering, Case Western Reserve University, Cleveland, OH, United States, ${ }^{7}$ Department of Engineering Cybernetics, Norwegian University of Science and Technology, Trondheim, Norway, ${ }^{8}$ Department of Animal and Food Science, Autonomous University of Barcelona, Barcelona, Spain, ${ }^{9}$ Moss Landing Marine Labs at San Jose State University, Moss Landing, CA, United States, ${ }^{10}$ Sea Mammal Research Unit, University of St. Andrews, Scotland, United Kingdom, ${ }^{11}$ Akkeshi Marine Station, Field Science Center for Northern Biosphere, Hokkaido University, Akkeshi, Japan, ${ }^{12}$ Rothamsted Research North Wyke, Okehampton, United Kingdom, ${ }^{13}$ Centre D'Etudes Biologiques de Chizé, La Rochelle Université, UMR7372, CNRS, France, ${ }^{14}$ Department of Biology, University of Southern Denmark, Odense, Denmark
\end{abstract}

Keywords: bio-logging, bio-telemetry, physiology, heart rate, accelerometers, welfare, conservation

\section{INTRODUCTION}

The field of bio-sensing refers to studies where the physiology of an animal, its behavior and movement, as well as the characteristics of the environment it moves in, is measured either by electronic sensor-carrying devices that store the data (bio-logging), or those that transmit the data directly (bio-telemetry). ${ }^{1}$ One of the first bio-sensing studies was conducted over 80 years ago with the attachment of a capillary tube to a fin whale (Balaenoptera physalus) to assess the dive depth of a free-ranging marine mammal (Scholander, 1940). In humans, the stethoscope was developed by Rene Laennec in 1819 as the first non-invasive heart monitor, which solved the challenge of listening to the heart by placing an ear on the patient's chest (not always welcome in the Victorian era) (Roguin, 2006). Quickly the system found new uses eventually leading to a shift from subjective to objective data about the internal body. The field of bio-sensing has since increased exponentially and revolutionized our understanding of animal ecology. With the technological development of miniaturized sensors, numerous studies of movement ecology, behavior, and communication in a diverse range of animals (e.g., species of fish, reptiles, birds and mammals) have been reviewed in (Frost et al., 1997; Davis, 2008; Ropert-Coudert et al., 2009a; Rutz and Hays, 2009; Swain et al., 2011; Hussey et al., 2015; Wilmers et al., 2015; Endo and Wu, 2019; Börger et al., 2020; Wassmer et al., 2020). While determining the physiological limits and plasticity of a species is essential for understanding its ecology and evolution, studies that measure the physiological responses of free-ranging animals (i.e., physio-logging) have not seen the same exponential increase, even though physiological questions were at the origin of the use of data loggers in seminal work done by field physiologists such as Gerry Kooyman, Paul Ponganis, Warren Zapol, and Patrick Butler (Butler and Woakes, 1979; Falke et al., 1985; Kooyman, 1985; Ponganis et al., 1991).

\footnotetext{
${ }^{1}$ Recent advances combine the logging and transmission of data using AI and machine learning approaches to process data on-board the logger and transmit either subsets of data or information derived from the primary data recorded.
} 
The slower growth of the physio-logging field could be due to the commercial unavailability of physiological sensors, or that the available sensors were too large, based on static-technologies, or required specialized surgical training and extensive knowledge of the anatomy and physiology of the animal for successful implantation. Despite these challenges, studies using bio-sensing tools have renewed the interest in physio-logging and attempted to understand the physiology of an animal through inference from their behavior (Wilson et al., 2002; Hooker et al., 2009; Goldbogen et al., 2011, 2019b; Kolarevic et al., 2016; Føre et al., 2018b; Quick et al., 2020).

Physio-loggers have recently been used on farmed animals (livestock) to record physiological variables (e.g., body temperature, respiration and heart rates) in order to monitor water intake, the occurrence of diseases, energy expenditure in grazing activities, and effect of diet on body temperature under cold and warm conditions (Brosh et al., 2006; Eigenberg et al., 2008; AlZahal et al., 2011; Arias et al., 2011; Aharoni et al., 2013; Cantor et al., 2018). In the human arena - where early biotelemetry approaches were born - technological advances such as movement sensors initially allowed anyone with a "smartphone" or "smartwatch" to assess their daily energy consumption, leading to the so-called "quantified health" movement (Scully et al., 2012). Indeed, subsequent development of non-invasive sensing (photoplethysmography) enabled new and exciting possibilities to track health and fitness in a large number of people (Dörr et al., 2019; Seshadri et al., 2020). In addition, recent developments in wearable medical and nanotechnology, with increased battery life, storage capacity and a range of sensors have increased our ability to study physiological function both non-invasively and continuously over months and years (Kang et al., 2016; Kaidarova et al., 2018, 2019; Lee et al., 2019; Lazaro et al., 2020). Thus, tools capable of measuring a range of important and informative physiological parameters are now available, and are continuously being improved and adapted to work on an increasing range of species. These developments will revolutionize the capacity to measure and assess the physiology of animals and humans over extended periods of time, which will allow a comprehensive evaluation of the physiological function of animals in their natural environment. This new era of physio-logging will enable long-term studies to better understand fundamental physiological function, health, welfare or well-being of animals and humans, as well as their responses to environmental and/or anthropogenic changes.

\section{THE PARADIGM SHIFT CHALLENGE}

Much of what we know about animal physiology has been obtained by measuring physiological parameters on captive, semi-captive, or restrained animals including measures of heart rate, blood flow, blood chemistry, blood gases, and metabolic rate (Berkson, 1967; Kooyman et al., 1970; Kooyman and Campbell, 1972; Kooyman and Sinnett, 1982; Lutcavage et al., 1989; Ponganis et al., 1990; Reed et al., 1994, 2000; Gräns et al., 2010; Kang et al., 2016; Brijs et al., 2018; Berenbrink, 2021; Svendsen et al., 2021). Unfortunately, in such situations, it is difficult to assess the magnitude of potential confounding factors such as stress or manipulation on the measured physiological variable. In recent years, there has been a focus on measuring physiology in free-ranging animals. For example, trained animals that are desensitized to the experimental procedures have been used to study diving energetics, cardiorespiratory and vascular physiology, and cerebrovascular physiology (Elsner, 1965; Olsen et al., 1969; Ridgway and Howard, 1979; Williams et al., 1993; Hurley and Costa, 2001; Fahlman et al., 2008, 2019, 2020a,b; Mortola and Sequin, 2009; Rosen and Trites, 2013; Worthy et al., 2013; Elmegaard et al., 2016, 2019; Takei et al., 2016; McKnight et al., 2019; Meir et al., 2019; Pedersen et al., 2020; Blawas et al., 2021). As bio-logging technologies have advanced, physiological parameters such as heart rate, respiration rate, and blood $\mathrm{O}_{2}$ have even been measured in free-ranging fish, reptiles, birds, and mammals (Falke et al., 1985; Ponganis et al., 1991; Thompson and Fedak, 1993; Southwood et al., 1999; Andrews et al., 2000; Froget et al., 2004; Ropert-Coudert et al., 2006, 2009b; Meir et al., 2009; Yamamoto et al., 2009; Meir and Ponganis, 2010; McDonald and Ponganis, 2013, 2014; Sakamoto et al., 2013; Duriez et al., 2014; Goldbogen et al., 2019a; McKnight et al., 2019, 2021a,b; Sumich, 2021). There is a parallel shift in the paradigm of physiological monitoring of humans. Whereas once health monitoring was exclusively a physician-based in-patient activity, the emergence of health and fitness wearables has led to the so-called "quantified self" movement, where patients are producing data in support of diagnostics (Patel and Tarakji, 2021).

\section{TECHNOLOGICAL DEVELOPMENT}

Progress on medical sensing technology has increased significantly. A wide range of physiological monitoring technologies are now available and are setting the stage from which physiological bio-sensing could profit immensely. For instance, virtually anyone with a "smartphone" or "smartwatch" can now assess their daily calorie expenditure as sensors within the phone can estimate the number of steps taken or distance moved. Similarly, researchers have applied this principle to free-ranging animals and are able to derive an estimate of energy expended in the wild via a measure of dynamic body movements measured by animal-embarked accelerometers (Wilson et al., 2006, 2020; Gleiss et al., 2011) that correlates well with other direct measures of energy expended even in wild animals (Elliott et al., 2013; Jeanniard-Du-Dot et al., 2017; Hicks et al., 2020). Phonospirometry (i.e., the use of the breath sound to estimate respiratory flow) is being used to perform lung function testing in both humans and animals (Sumich and May, 2009; Larson et al., 2012; Sumich, 2021; Van Der Hoop et al., 2021). In addition, the ongoing development of wearable medical sensors that can detect glucose levels, estimate heart rate via waterproof ECG electrodes (Reyes et al., 2014; Noh et al., 2016) or assess blood flow/volume changes and/or blood oxygen saturation changes provide a particularly exciting avenue for future research (Bockstaele et al., 2014; McKnight et al., 2019, 2021a,b). These technological advancements open up enormous possibilities as they will enable investigating the physiological 
function in freely moving, and even free-ranging animals, with minimal disturbances. Further, the development of fully bioresorbable microchip technologies capable of measuring a variety of physiological parameters (Kang et al., 2016) could offer opportunities to measure new, fine-scale physiological metrics in free-moving and free-ranging animals. Thus, long-term data sets on movement, married with physiological data could become available, contributing essential components to frameworks that assess the consequences of environmental and/or anthropogenic impacts such as Population Consequences of Disturbance (PCoD, Booth et al., 2014; Pirotta et al., 2018), as well as to develop a fundamental understanding of the physiology of a diverse range of species.

\section{ANALYTICAL DEVELOPMENT}

The collection of long-term and/or high-resolution data sets is likely to result in analytical challenges. For example, ECG collection sampled at $200 \mathrm{~Hz}$ over a whole year results in 6.3 billion data points. While ECG could be reduced to instantaneous heart rate (if $f_{H}$ ) (Sakamoto et al., 2021), normal statistical tools, such as comparison of means or medians are not applicable and are likely to result in erroneous conclusions. More sophisticated analytical methods, including signal processing or time-series analysis, will have to be developed and introduced to deal with a growing number of studies that focus on physiological function and eco-physiology. There has recently been a rapid growth in analytical techniques in bioinformatics, where new tools and databases have been developed to handle the large data sets that result from sequencing the genome of various species and to evaluate gene networks and differential changes in molecular products. A similar exponential growth has been seen within data processing methods based on Artificial Intelligence (AI) and Machine Learning (ML). These methods are used in several different fields today, especially when data sets are too large and/or complex to handle through conventional means, and it is likely that they prove useful for processing datasets from biosensors. Although many AI/ML methods are "a black box," in the sense that they do not describe the mechanistic links between input and output (e.g., environmental and/or anthropogenic changes and sensor output in this case), they could be useful for compressing and condensing large data sets and identifying unknown relationships between inputs and measured features (Rasheed et al., 2020).

\section{CONCLUSION}

In the last 40 years, the field of bio-sensing has provided important information about the ecology and behavior of wild animals, largely focusing on describing where they go and what they do there. Animal tracking studies have substantially improved the knowledge of movement patterns and drivers of movement in marine, terrestrial and avian species. However, the rapid development and miniaturization of bio-sensing electronics capable of measuring a raft of physiological variables present innovative and exciting tools that will revolutionize this field of research and usher in a new era of physio-logging. These technologies will allow us to comprehensively evaluate how and why animals make the journeys they do (e.g., bar-headed geese flying over the Himalayas, Cuvier's beaked whales diving to $3000 \mathrm{~m}$ for over $3 \mathrm{~h}$; Hawkes et al., 2013; Quick et al., 2020). Such studies will provide a foundation for understanding how animals may respond to alterations in the environment and the physiological boundaries for survival. Physio-logging can also provide the necessary tools for conservation management, which will contribute toward reducing the impacts of anthropogenic disturbances on species, communities and even ecosystems. For example, assessment of stress levels, such as measuring corticosterone or heart rate may help evaluate the impact of anthropogenetic disturbance (Miksis et al., 2001). Furthermore, physio-logging is also likely to provide an important diagnostic tool for evaluating the well-being and welfare of farmed terrestrial and aquatic animals. These technologies can provide a unique opportunity for health monitoring via an "animal-eye" view of the conditions that farmed animals experience in human care on a day-to-day basis, enabling a better understanding of how to address the challenges faced by industries attempting to produce a profitable, ethical and environmentally sustainable product (Berckmans, 2004; Føre et al., 2018a; Brijs et al., 2021). Many of the responses evaluated in these managed settings could also be translated to wild animals given the clear link between physiology and welfare (Gregory, 2004; Baird et al., 2016; Føre et al., 2018a; Svendsen et al., 2021). Finally, physiologging is likely to promote improved health and wellness in humans, where early detection of disease allows improved treatment outcome.

As we enter a new age in the study of physiology of animals and humans living in complex environments, the Physiologging journal aims to provide a forum where scientists, and conservation practitioners among others, can share knowledge on how modern sensing technology and analytical approaches can be used to understand physiological function and health of animals and humans.

\section{AUTHOR CONTRIBUTIONS}

All authors listed have made a substantial, direct and intellectual contribution to the work, and approved it for publication.

\section{REFERENCES}

Aharoni, Y., Dolev, A., Henkin, Z., Yehuda, Y., Ezra, A., Ungar, E. D., et al. (2013). Foraging behavior of two cattle breeds, a whole-year study: I. Heat production, activity, and energy costs1. J. Anim. Sci. 91, 1381-1390. doi: $10.2527 /$ jas.2012-5400

AlZahal, O., AlZahal, H., Steele, M. A., Van Schaik, M., Kyriazakis, I., Duffield, T. F., et al. (2011). The use of a radiotelemetric ruminal bolus to detect body temperature changes in lactating dairy cattle. J. Dairy Sci. 94, 3568-3574. doi: 10.3168/jds.2010-3944

Andrews, R. D., Costa, D. P., Leboeuf, B. J., and Jones, D. R. (2000). Breathing frequencies of northern elephant seals at sea and on land 
revealed by heart rate spectral analysis. Respir. Physiol. 123, 71-85. doi: 10.1016/S0034-5687(00)00168-7

Arias, R. A., Mader, T. L., and Parkhurst, A. M. (2011). Effects of diet type and metabolizable energy intake on tympanic temperature of steers fed during summer and winter seasons. J. Anim. Sci. 89, 1574-1580. doi: $10.2527 /$ jas.2010-2975

Baird, B. A., Kuhar, C. W., Lukas, K. E., Amendolagine, L. A., Fuller, G. A., Nemet, J., et al. (2016). Program animal welfare: using behavioral and physiological measures to assess the well-being of animals used for education programs in zoos. Appl. Anim. Behav. Sci. 176, 150-162. doi: 10.1016/j.applanim.2015.12.004

Berckmans, D. (2004). "Automatic on-line monitoring of animals by precision livestock farming," in Proceedings of the ISAH Conference on Animal Production in Europe: The Way Forward in a Changing World, Vol. 1 (Saint-Malo), 27-31.

Berenbrink, M. (2021). The role of myoglobin in the evolution of mammalian diving capacity - The August Krogh principle applied in molecular and evolutionary physiology. Comp. Biochem. Physiol. Part A Mol. Integr. Physiol. 252:110843. doi: 10.1016/j.cbpa.2020.110843

Berkson, H. (1967). Physiological adjustments to deep diving in the pacific green turtle (Chelonia mydas agassizii). Comp. Biochem. Physiol. 21, 507-524. doi: 10.1016/0010-406X(67)90448-3

Blawas, A. M., Nowacek, D. P., Allen, A., Rocho-Levine, J., and Fahlman, A. (2021). Respiratory sinus arrhythmia and submersion bradycardia in bottlenose dolphins (Tursiops truncatus). J. Exp. Biol. 224. doi: 10.1242/jeb.234096

Bockstaele, R., Ryckeboer, E., Hattasan, N., De Koninck, Y., Muneeb, M., and Verstuyft, S. (2014). "Glucose sensing by means of silicon photonics," in: Proc.SPIE. San Francisco, CA.

Booth, C., Donovan, C., King, S., and Schick, R. (2014). A protocol for implementing the interim Population Consequences of Disturbance (PCoD) approach: quantifying and assessing the effects of UK offshore renewable energy developments on marine mammal populations. Scot. Mar. Freshw. Sci. 5:90. doi: $10.7489 / 1486-1$

Börger, L., Bijleveld, A. I., Fayet, A. L., Machovsky-Capuska, G. E., Patrick, S. C., Street, G. M., et al. (2020). Biologging Special Feature. J. Anim. Ecol. 89, 6-15. doi: 10.1111/1365-2656.13163

Brijs, J., Føre, M., Gräns, A., Clark, T. D., Axelsson, M., and Johansen, J. (2021). "Bio-sensing technologies in aquaculture: how remote monitoring can bring us closer to our farm animals," in Philosophical Transactions of the Royal Society B. doi: 10.1098/rstb.2020.0218

Brijs, J., Sandblom, E., Axelsson, M., Sundell, K., Sundh, H., Huyben, D., et al. (2018). The final countdown: Continuous physiological welfare evaluation of farmed fish during common aquaculture practices before and during harvest. Aquaculture 495, 903-911. doi: 10.1016/j.aquaculture.2018.06.081

Brosh, A., Henkin, Z., Ungar, E. D., Dolev, A., Orlov, A., Yehuda, Y., et al. (2006). Energy cost of cows' grazing activity: use of the heart rate method and the Global Positioning System for direct field estimation1. J. Anim. Sci. 84, 1951-1967. doi: 10.2527/jas.2005-315

Butler, P. J., and Woakes, A. J. (1979). Changes in heart rate and respiratory frequency during natural behaviour of ducks, with particular reference to diving. J. Exp. Biol. 79, 283-300.

Cantor, M. C., Costa, J. H. C., and Bewley, J. M. (2018). Impact of observed and controlled water intake on reticulorumen temperature in lactating dairy cattle. Animals 8. doi: 10.3390/ani8110194

Davis, R. W. (2008). "Bio-logging as a method for understanding natural systems," in International Conference on Informatics Education and Research for Knowledge-Circulating Society (icks 2008) (Kyoto), 12-17. doi: 10.1109/ICKS.2008.13

Dörr, M., Nohturfft, V., Brasier, N., Bosshard, E., Djurdjevic, A., Gross, S., et al. (2019). The WATCH AF Trial: SmartWATCHes for detection of atrial fibrillation. JACC Clin. Electrophysiol. 5, 199-208. doi: $10.1016 /$ j.jacep.2018.10.006

Duriez, O., Kato, A., Tromp, C., Dell'omo, G., Vyssotski, A. L., Sarrazin, F., et al. (2014). How cheap is soaring flight in raptors? A preliminary investigation in freely-flying vultures. PLoS ONE 9, e84887. doi: 10.1371/journal.pone.0084887

Eigenberg, R. A., Brown-Brandl, T. M., and Nienaber, J. A. (2008). Sensors for dynamic physiological measurements. Comp. Electron. Agric. 62, 41-47. doi: 10.1016/j.compag.2007.08.011
Elliott, K. H., Le Vaillant, M., Kato, A., Speakman, J. R., and Ropert-Coudert, Y. (2013). Accelerometry predicts daily energy expenditure in a bird with high activity levels. Biol. Lett. 9, 20120919. doi: 10.1098/rsbl.2012.0919

Elmegaard, S. L., Johnson, M., Madsen, P. T., and McDonald, B. I. (2016). Cognitive control of heart rate in diving harbor porpoises. Curr. Biol. 26, R1167-R1176. doi: 10.1016/j.cub.2016.10.020

Elmegaard, S. L., McDonald, B. I., and Madsen, P. T. (2019). Drivers of the dive response in trained harbour porpoises (Phocoena phocoena). J. Exp. Biol. 222:jeb208637. doi: $10.1242 /$ jeb.208637

Elsner, R. (1965). Heart rate response in forced versus trained experimental dives in pinnipeds. Hvalrådets Skrifter 48, 24-29.

Endo, H., and Wu, H. (2019). Biosensors for the assessment of fish health: a review. Fish. Sci. 85, 641-654. doi: 10.1007/s12562-019-01318-y

Fahlman, A., Cozzi, B., Manley, M., Jabas, S., Malik, M., Blawas, A., et al. (2020a). Conditioned variation in heart rate during static breath-holds in the bottlenose dolphin (Tursiops truncatus) Frontiers. Physiology 11:604018. doi: $10.3389 /$ fphys.2020.604018

Fahlman, A., Miedler, S., Marti-Bonmati, L., Ferrero Fernandez, D., Muñoz Caballero, P., Arenarez, J., et al. (2020b). Cardiorespiratory coupling in cetaceans; a physiological strategy to improve gas exchange? J. Exp. Biol. 223:jeb226365. doi: $10.1242 /$ jeb.226365

Fahlman, A., Miedler, S., Rocho-Levine, J., Jabois, A., Arenarez, J., Marti-Bonmati, L., et al. (2019). Re-evaluating the significance of the dive response during voluntary surface apneas in the bottlenose dolphin, Tursiops truncatus. Sci. Rep. 9:8613. doi: 10.1038/s41598-019-45064-8

Fahlman, A., Svärd, C., Rosen, D.,a,.S., Jones, D. R., and Trites, A.W. (2008). Metabolic costs of foraging and the management of $\mathrm{O} 2$ and $\mathrm{CO} 2$ stores in Steller sea lions. J. Exp. Biol. 211, 3573-3580. doi: 10.1242/jeb.023655

Falke, K. J., Hill, R. D., Qvist, J., Schneider, R. C., Guppy, M., Liggins, G. C., et al. (1985). Seal lung collapse during free diving: evidence from arterial nitrogen tensions. Science 229, 556-557. doi: 10.1126/science.4023700

Føre, M., Frank, K., Norton, T., Svendsen, E., Alfredsen, J. A., Dempster, T., et al. (2018a). Precision fish farming: a new framework to improve production in aquaculture. Biosyst. Eng. 173, 176-193. doi: 10.1016/j.biosystemseng.2017.10.014

Føre, M., Svendsen, E., Alfredsen, J. A., Uglem, I., Bloecher, N., Sveier, H., et al. (2018b). Using acoustic telemetry to monitor the effects of crowding and delousing procedures on farmed Atlantic salmon (Salmo salar). Aquaculture 495, 757-765. doi: 10.1016/j.aquaculture.2018.06.060

Froget, G., Butler, P. J., Woakes, A. J., Fahlman, A., Kuntz, G., Le Maho, Y., et al. (2004). Heart rate and energetics of free-ranging king penguins (Aptenodytes patagonicus). J. Exp. Biol. 207, 3917-3926. doi: 10.1242/jeb.01232

Frost, A. R., Schofield, C. P., Beaulah, S. A., Mottram, T. T., Lines, J. A., and Wathes, C. M. (1997). A review of livestock monitoring and the need for integrated systems. Comp. Electron. Agric. 17, 139-159. doi: 10.1016/S0168-1699(96)01301-4

Gleiss, A. C., Wilson, R. P., and Shepard, E. L. C. (2011). Making overall dynamic body acceleration work: on the theory of acceleration as a proxy for energy expenditure. Methods Ecol. Evol. 2, 23-33. doi: 10.1111/j.2041-210X.2010.00057.x

Goldbogen, J. A., Cade, D. E., Calambokidis, J., Czapanskiy, M. F., Fahlbusch, J., Friedlaender, A. S., et al. (2019a). Extreme bradycardia and tachycardia in the world's largest animal. Proc. Natl. Acad. Sci. U. S. A. 116, 25329-32. doi: $10.1073 /$ pnas. 1914273116

Goldbogen, J. A., Cade, D. E., Wisniewska, D. M., Potvin, J., Segre, P. S., Savoca, M. S., et al. (2019b). Why whales are big but not bigger: physiological drivers and ecological limits in the age of ocean giants. Science 366, 1367-1372. doi: $10.1126 /$ science.aax 9044

Goldbogen, J. A., Calambokidis, J., Oleson, E., Potvin, J., Pyenson, N. D., Schorr, G., et al. (2011). Mechanics, hydrodynamics and energetics of blue whale lunge feeding: efficiency dependence on krill density. J. Exp. Biol. 214, 131-146. doi: $10.1242 /$ jeb. 048157

Gräns, A., Olsson, C., Pitsillides, K., Nelson, H. E., Cech, J. J., and Axelsson, M. (2010). Effects of feeding on thermoregulatory behaviours and gut blood flow in white sturgeon (Acipenser transmontanus) using biotelemetry in combination with standard techniques. J. Exp. Biol. 213, 3198-3206. doi: 10.1242/jeb. 043570 
Gregory, N. G. (2004). Physiology and Behaviour of Animal Suffering. Oxford: Blackwell Science.

Hawkes, L. A., Balachandran, S., Batbayar, N., Butler, P. J., Chua, B., Douglas, D. C., et al. (2013). The paradox of extreme high-altitude migration in bar-headed geese Anser indicus. Proc. R. Soc. B Biol. Sci. 280:20122114. doi: $10.1098 /$ rspb.2012.2114

Hicks, O., Kato, A., Angelier, F., Wisniewska, D. M., Hambly, C., Speakman, J. R., et al. (2020). Acceleration predicts energy expenditure in a fat, flightless, diving bird. Sci. Rep. 10:21493. doi: 10.1038/s41598-020-78025-7

Hooker, S. K., Baird, R. W., and Fahlman, A. (2009). Could beaked whales get the bends? Effect of diving behaviour and physiology on modelled gas exchange for three species: Ziphius cavirostris, Mesoplodon densirostris and Hyperoodon ampullatus. Respir. Physiol. Neurobiol. 167, 235-246. doi: $10.1016 /$ j.resp.2009.04.023

Hurley, J. A., and Costa, D. P. (2001). Standard metabolic rate at the surface and during trained submersions in adult California sea lions (Zalophus californianus). J. Exp. Biol. 204, 3273-3281.

Hussey, N. E., Kessel, S. T., Aarestrup, K., Cooke, S. J., Cowley, P. D., Fisk, A. T., et al. (2015). Aquatic animal telemetry: A panoramic window into the underwater world. Science 348:1255642. doi: 10.1126/science.1255642

Jeanniard-Du-Dot, T., Trites, A. W., Arnould, J. P. Y., Speakman, J. R., and Guinet, C. (2017). Activity-specific metabolic rates for diving, transiting, and resting at sea can be estimated from time-activity budgets in free-ranging marine mammals. Ecol. Evol. 7, 2969-2976. doi: 10.1002/ece3.2546

Kaidarova, A., Khan, M. A., Marengo, M., Swanepoel, L., Przybysz, A., Muller, C., et al. (2019). Wearable multifunctional printed graphene sensors. npj Flex. Electron. 3:15. doi: 10.1038/s41528-019-0061-5

Kaidarova, A., Marengo, M., Marinaro, G., Geraldi, N., Duarte, C. M., and Kosel, J. (2018). Flexible and biofouling independent salinity sensor. Adv. Mater. Interfaces 5:1801110. doi: 10.1002/admi.201801110

Kang, S. K., Murphy, R. K., Hwang, S. W., Lee, S. M., Harburg, D. V., Krueger, N. A., et al. (2016). Bioresorbable silicon electronic sensors for the brain. Nature 530, 71-76. doi: 10.1038/nature16492

Kolarevic, J., Aas-Hansen, Ø., Espmark, Å., Baeverfjord, G., Terjesen, B. F., and Damsgård, B. (2016). The use of acoustic acceleration transmitter tags for monitoring of Atlantic salmon swimming activity in recirculating aquaculture systems (RAS). Aquac. Eng. 72-73, 30-39. doi: 10.1016/j.aquaeng.2016.03.002

Kooyman, G. L. (1985). Physiology without restraint in diving mammals. Science 1, 166-178. doi: 10.1111/j.1748-7692.1985.tb00004.x

Kooyman, G. L., and Campbell, W. B. (1972). Heart rates in freely diving weddell seals, Leptonychotes weddelli. Comp. Biochem. Physiol. Part A Physiol. 43, 31-36. doi: 10.1016/0300-9629(72)90465-3

Kooyman, G. L., Hammond, D. D., and Schroede, J. P. (1970). Bronchograms and tracheograms of seals under pressure. Science 169, 82-84. doi: $10.1126 /$ science. 169.3940 .82

Kooyman, G. L., and Sinnett, E. E. (1982). Pulmonary shunts in Harbor seals and sea lions during simulated dives to depth. Physiol. Zool. 55, 105-111. doi: 10.1086/physzool.55.1.30158447

Larson, E. C., Goel, M., Boriello, G., Heltshe, S., Rosenfeld, M., and Patel, S. N. (2012). "SpiroSmart: using a microphone to measure lung function on a mobile phone," in Proceedings of the 2012 ACM Conference on Ubiquitous Computing (Pittsburgh, PA: Association for Computing Machinery).

Lazaro, J., Reljin, N., Hossain, M. B., Noh, Y., Laguna, P., and Chon, K. H. (2020). Wearable armband device for daily life electrocardiogram monitoring. IEEE Trans. Biomed. Eng. 67, 3464-3473. doi: 10.1109/TBME.2020.2987759

Lee, M. A., Nguyen, F. T., Scott, K., Chan, N. Y. L., Bakh, N. A., Jones, K. K., et al. (2019). Implanted nanosensors in marine organisms for physiological biologging: design, feasibility, and species variability. ACS Sens. 4, 32-43. doi: 10.1021/acssensors.8b00538

Lutcavage, M. E., Lutz, P. L., and Baier, H. (1989). Respiratory mechanics of the loggerhead sea turtle, Caretta caretta. Respir. Physiol. 76, 13-24. doi: 10.1016/0034-5687(89)90014-5

McDonald, B. I., and Ponganis, P. J. (2013). Insights from venous oxygen profiles: oxygen utilization and management in diving California sea lions. J. Exp. Biol. 216, 3332-3341. doi: 10.1242/jeb.085985

McDonald, B. I., and Ponganis, P. J. (2014). Deep-diving sea lions exhibit extreme bradycardia in long duration dives. J. Exp. Biol. 217, 1525-1534. doi: $10.1242 / \mathrm{jeb} .098558$
McKnight, J. C., Bennett, K. A., Bronkhorst, M., Russell, D. J. F., Balfour, S., Milne, R., et al. (2019). Shining new light on mammalian diving physiology using wearable near-infrared spectroscopy. PLOS Biol. 17:e3000306. doi: 10.1371/journal.pbio.3000306

McKnight, J. C., Mulder, E., Ruesch, A., Kairnerstorfer, J., Wu, J., Hakimi, N., et al. (2021a). "When the human brain goes diving: using NIRS to measure cerebral and systemic cardiovascular responses to deep, breath-hold diving in elite freedivers," in Philosophical Transaction of the Royal Society London B. doi: 10.1098/rstb.2020.0349

McKnight, J. C., Ruesch, A., Bennett, K., Bronkhorst, M., Balfour, S., Moss, S. E. W., et al. (2021b). "Shining new light on sensory brain activation and physiological measurement in seals using wearable optical technology," in Philosophical Transaction of the Royal Society London B. doi: 10.1098/rstb.2020.0224

Meir, J. U., Champagne, C. D., Costa, D. P., Williams, C. L., and Ponganis, P. J. (2009). Extreme hypoxemic tolerance and blood oxygen depletion in diving elephant seals. Am. J. Physiol. Regul. Integr. Comp. Physiol. 297, R927-939. doi: 10.1152/ajpregu.00247.2009

Meir, J. U., and Ponganis, P. J. (2010). Blood temperature profiles of diving elephant seals. Physiol. Biochem. Zool. 83, 531-540. doi: 10.1086/651070

Meir, J. U., York, J. M., Chua, B. A., Jardine, W., Hawkes, L. A., and Milsom, W. K. (2019). Reduced metabolism supports hypoxic flight in the high-flying bar-headed goose (Anser indicus). eLife 8:e44986. doi: 10.7554/eLife.44986.023

Miksis, J. L., Grund, M. D., Nowacek, D. P., Solow, A. R., Connor, R. C., and Tyack, P. L. (2001). Cardiac respones to acoustic playback experiments in the captive bottlenose dolphin (Tursiops truncatus). J. Comp. Psychol. 115, 227-232. doi: $10.1037 / 0735-7036.115 .3 .227$

Mortola, J. P., and Sequin, J. (2009). End-tidal CO2 in some aquatic mammals of large size. Zoology 112, 77-85. doi: 10.1016/j.zool.2008.06.001

Noh, Y., Bales, J., Reyes, B., Molignano, J., Clement, A. L., Pins, G. D., et al. (2016). A copper-meshed $\mathrm{CB} / \mathrm{PDMS}$ electrode for underwater ECG monitoring: comparison with commercial electrodes in fresh, salt, \& chlorine water. Ann. $B M E$ 44, 2464-2479. doi: 10.1007/s10439-015-1528-8

Olsen, C. R., Hale, F. C., and Elsner, R. (1969). Mechanics of ventilation in the pilot whale. Respir. Physiol. 7, 137-149. doi: 10.1016/0034-5687(69)90001-2

Patel, D., and Tarakji, K. G. (2021). Smartwatch diagnosis of atrial fibrillation in patient with embolic stroke of unknown source: a case report. Cardiovasc. Dig. Health J. 2, 84-87. doi: 10.1016/j.cvdhj.2021.01.001

Pedersen, M. B., Fahlman, A., Borque-Espinosa, A., Madsen, P. T., and Jensen, F. H. (2020). Whistling is metabolically cheap for communicating bottlenose dolphins (Tursiops truncatus). J. Exp. Biol. 223:jeb.212498. doi: $10.1242 / \mathrm{jeb} .212498$

Pirotta, E., Booth, C. G., Costa, D. P., Fleishman, E., Kraus, S. D., Lusseau, D., et al. (2018). Understanding the population consequences of disturbance. Ecol. Evol. 8, 9934-9946. doi: 10.1002/ece3.4458

Ponganis, P. J., Kooyman, G. L., and Zornow, M. H. (1991). Cardiac output in swimming California sea lions, Zalophus californianus. Physiol. Zool. 64, 1296-1306. doi: 10.1086/physzool.64.5.30156246

Ponganis, P. J., Kooyman, G. L., Zornow, M. H., Castellini, M. A., and Croll, D. A. (1990). Cardiac output and stroke volume in swimming harbor seals. J. Comp. Physiol. B 160, 473-482. doi: 10.1007/BF00258974

Quick, N. J., Cioffi, W. R., Shearer, J. M., Fahlman, A., and Read, A. J. (2020). Extreme diving in mammals: first estimates of behavioural aerobic dive limits in Cuvier's beaked whales. J. Exp. Biol. 225:jeb222109. doi: 10.1242/jeb.222109

Rasheed, A., San, O., and Kvamsdal, T. (2020). Digital twin: values, challenges and enablers from a modeling perspective. IEEE Access 8, 21980-22012. doi: 10.1109/ACCESS.2020.2970143

Reed, J. Z., Chambers, C., Fedak, M. A., and Butler, P. J. (1994). Gas exchange of captive freely diving grey seals (Halichoerus grypus). J. Exp. Biol. 191, 1-18.

Reed, J. Z., Chambers, C., Hunter, C. J., Lockyer, C., Kastelein, R., Fedak, M. A., et al. (2000). Gas exchange and heart rate in the harbour porpoise, Phocoena phocoena. J. Comp. Physiol. B 170, 1-10. doi: 10.1007/s003600050001

Reyes, B. A., Posada-Quintero, H. F., Bales, J. R., Clement, A. L., Pins, G. D., Swiston, A., et al. (2014). Novel electrodes for underwater ECG monitoring. IEEE Trans. Biomed. Eng. 61, 1863-1876. doi: 10.1109/TBME.2014.230 9293

Ridgway, S. H., and Howard, R. (1979). Dolphin lung collapse and intramuscular circulation during free diving: evidence from nitrogen washout. Science 206, 1182-1183. doi: $10.1126 /$ science. 505001 
Roguin, A. (2006). Rene Theophile Hyacinthe Laënnec (1781-1826): the man behind the stethoscope. Clin. Med. Res. 4, 230-235. doi: 10.3121/cmr.4.3.230

Ropert-Coudert, Y., Beaulieu, M., Hanuise, N., and Kato, A. (2009a). Diving into the world of biologging. Endang. Species Res. 10, 21-27. doi: 10.3354/esr00188

Ropert-Coudert, Y., Brooks, L., Yamamoto, M., and Kato, A. (2009b). ECG response of koalas to tourists proximity: a preliminary study. PLOS ONE 4:e7378. doi: 10.1371/journal.pone.0007378

Ropert-Coudert, Y., Wilson, R. P., Gremillet, D., Kato, A., Lewis, S., and Ryan, P. G. (2006). Electrocardiogram recordings in free-ranging gannets reveal minimum difference in heart rate during flapping versus gliding flight. Marine Ecol. Progr. Ser. 328, 275-284. doi: 10.3354/meps328275

Rosen, D. S., and Trites, A.W. (2013). Resting metabolic rate of a mature male beluga whale (Delphinapterus leucas). Aquat. Mammals 39, 85-88. doi: 10.1578/AM.39.1.2013.85

Rutz, C., and Hays, G. C. (2009). New frontiers in biologging science. Biol. Lett. 5, 289-292. doi: 10.1098/rsbl.2009.0089

Sakamoto, K. Q., Miyayama, M., Kinoshita, C., Fukuoka, T., Ishihara, T., and Sato, K. (2021). "A non-invasive system to measure heart rate in hard-shelled sea turtles: Potential for field applications," in Philosophical Transaction of the Royal Society London B. doi: 10.1098/rstb.2020.0222

Sakamoto, K. Q., Takahashi, A., Iwata, T., Yamamoto, T., Yamamoto, M., and Trathan, P. N. (2013). Heart rate and estimated energy expenditure of flapping and gliding in black-browed albatrosses. J. Exp. Biol. 216, 3175-3182. doi: $10.1242 /$ jeb.079905

Scholander, P. F. (1940). Experimental investigations on the respiratory function in diving mammals and birds. Hvalrådets Skrifter 22, 1-131.

Scully, C. G., Lee, J., Meyer, J., Gorbach, A. M., Granquist-Fraser, D., Mendelson, Y., et al. (2012). Physiological parameter monitoring from optical recordings with a mobile phone. IEEE Transact. Bio Med. Eng. 59, 303-306. doi: 10.1109/TBME.2011.2163157

Seshadri, D. R., Davies, E. V., Harlow, E. R., Hsu, J. J., Knighton, S. C., Walker, T. A., et al. (2020). Wearable sensors for COVID-19: a call to action to harness our digital infrastructure for remote patient monitoring and virtual assessments. Front. Dig. Health. 2. doi: 10.3389/fdgth.2020.00008

Southwood, A. L., Andrews, R. D., Lutcavage, M. E., Paladino, F. V., West, N. H., George, R. H., et al. (1999). Heart rates and diving behavior of leatherback sea turtles in the eastern pacific ocean. J. Exp. Biol. 202, 1115-1125.

Sumich, J. L. (2021). Why Baja? A bioenergetic model for comparing metabolic rates and thermoregulatory costs of gray whale calves (Eschrichtius robustus). Mar. Mam. Sci. 1-18. doi: 10.1111/mms.12778

Sumich, J. L., and May, M. A. (2009). Scaling and remote monitoring of tidal lung volumes of young gray whales, Eschrichtius robustus. Marine Mammal Sci. 25, 221-228. doi: 10.1111/j.1748-7692.2008.00272.x

Svendsen, E., Føre, M., Økland, F., Gräns, A., Hedger, R. D., Alfredsen, J. A., et al. (2021). Heart rate and swimming activity as stress indicators for Atlantic salmon (Salmo salar). Aquaculture 531:735804. doi: 10.1016/j.aquaculture.2020.735804

Swain, D. L., Friend, M. A., Bishop-Hurley, G. J., Handcock, R. N., and Wark, T. (2011). Tracking livestock using global positioning systems - are we still lost? Anim. Prod. Sci. 51, 167-175. doi: 10.1071/AN10255

Takei, Y., Suzuki, I., Wong, M. K. S., Milne, R., Moss, S., Sato, K., et al. (2016). Development of an animal-borne blood sample collection device and its deployment for the determination of cardiovascular and stress hormones in phocid seals. Am. J. Physiol. Regul. Integr. Comp. Physiol. 311, R788-R796. doi: 10.1152/ajpregu.00211.2016
Thompson, D., and Fedak, M. A. (1993). Cardiac responses of grey seals during diving at sea. J. Exp. Biol. 174, 139-154.

Van Der Hoop, J. M., Fahlman, A., Jensen, F. H., Beedholm, K., Rocho-Levine, J., Wells, R. S., et al. (2021). Free-ranging bottlenose dolphins meet changing respiratory demands by breathing with a low but variable tidal volume. Phil. Trans. B. doi: $10.1098 /$ rstb. 2020.0428

Wassmer, T., Jensen, F. H., Fahlman, A., and Murray, D. L. (2020). Editorial: ecology and behaviour of free-ranging animals studied by advanced data-logging and tracking techniques. Front. Ecol. Evol. 8. doi: $10.3389 /$ fevo.2020.00113

Williams, T. M., Friedl, W. A., and Haun, J. E. (1993). The physiology of bottlenose dolphins (Tursiops truncatus): heart rate, metabolic rate and plasma lactate concentration during exercise. J. Exp. Biol. 179, 31-46.

Wilmers, C. C., Nickel, B., Bryce, C. M., Smith, J. A., Wheat, R. E., and Yovovich, V. (2015). The golden age of bio-logging: how animal-blllorne sensors are advancing the frontiers of ecology. Ecology 96, 1741-1753. doi: 10.1890/14-1401.1

Wilson, R., Steinfurth, A., Ropert-Coudert, Y., Kato, A., and Kurita, M. (2002). Lip-reading in remote subjects: an attempt to quantify and separate ingestion, breathing and vocalisation in free-living animals using penguins as a model. Mar. Biol. 140, 17-27. doi: 10.1007/s0022701 00659

Wilson, R. P., Börger, L., Holton, M. D., Scantlebury, D. M., Gómez-Laich, A., Quintana, F., et al. (2020). Estimates for energy expenditure in free-living animals using acceleration proxies: A reappraisal. J. Anim. Ecol. 89, 161-172. doi: 10.1111/1365-2656.13040

Wilson, R. P., White, C. R., Quintana, F., Halsey, L. G., Liebsch, N., Martin, G. R., et al. (2006). Moving towards acceleration for estimates of activity-specific metabolic rate in free-living animals: the case of the cormorant. J. Anim. Ecol. 75, 1081-1090. doi: 10.1111/j.1365-2656.2006. 01127.x

Worthy, G. A. J., Worthy, T. A. M., Yochem, P. K., and Dold, C. (2013). Basal metabolism of an adult male killer whale (Orcinus orca). Mar. Mammal Sci. 30, 1229-1237. doi: 10.1111/mms.12091

Yamamoto, M., Kato, A., Ropert-Coudert, Y., Kuwahara, M., Hayama, S., and Naito, Y. (2009). Evidence of dominant parasympathetic nervous activity of great cormorants (Phalacrocorax carbo). J. Comp. Physiol. A Neuroethol. Sens. Neural Behav. Physiol. 195, 365-373. doi: 10.1007/s00359-0090414-y

Conflict of Interest: AF was employed without salary by the company Global Diving Research Inc.

The remaining authors declare that the research was conducted in the absence of any commercial or financial relationships that could be construed as a potential conflict of interest.

Copyright (๑) 2021 Fahlman, Aoki, Bale, Brijs, Chon, Drummond, Føre, Manteca, McDonald, McKnight, Sakamoto, Suzuki, Rivero, Ropert-Coudert and Wisniewska. This is an open-access article distributed under the terms of the Creative Commons Attribution License (CC BY). The use, distribution or reproduction in other forums is permitted, provided the original author(s) and the copyright owner(s) are credited and that the original publication in this journal is cited, in accordance with accepted academic practice. No use, distribution or reproduction is permitted which does not comply with these terms. 